\title{
Enantioselective Synthesis of Succinimides by Michael Addition of 1,3-Dicarbonyl Compounds to Maleimides Catalyzed by a Chiral Bis(2-aminobenzimidazole) Organocatalyst
}

\author{
Eduardo Gómez-Torres, ${ }^{[a]}$ Diego A. Alonso, ${ }^{[a] *}$ Enrique Gómez-Bengoa, ${ }^{[b]}$ and Carmen Nájera ${ }^{[a] *}$
}

Keywords: Asymmetric catalysis / Hydrogen bonding / Michael addition / Organocatalysis / Benzimidazole

A wide variety of chiral succinimides have been prepared in high yields and enantioselectivities by an asymmetric conjugate addition of 1,3-dicarbonyl compounds to maleimides under very mild reaction conditions using the bifunctional benzimidazole-derived organocatalyst $\mathbf{5 f}$.

[a] Departamento de Química Orgánica \& Instituto de Síntesis Orgánica Universidad de Alicante

Carretera de San Vicente del Raspeig s/n, E-03690, San Vicente del Raspeig, Alicante (Spain) Fax: (+34965903549)

E-mail: diego.alonso@ua.es; cnajera@ua.es

[b] Departamento de Química Orgánica I, Universidad del País Vasco, Apdo. 1072, E-20080 San Sebastián (Spain)

Supporting information for this article is available on the WWW under http://www.eurjoc.org/ or from the author.

\section{Introduction}

Cyclic imides play a vital role in polymer, biological, medicinal, and synthetic chemistry. ${ }^{[1]}$ In particular, succinimides are important building blocks usually present in natural products and drugs, such as phensuximide, ${ }^{[2]}$ ethosuximide, ${ }^{[3]}$ and andrimid ${ }^{[4]}$ (Figure 1).<smiles>CN1C(=O)CC(c2ccccc2)C1=O</smiles>

Phensuximide<smiles>CCC1(C)CC(=O)NC1=O</smiles>

Ethosuximide<smiles>C/C=C/C=C/C=C/C(=O)N[C@H](CC(=O)NC1C(=O)C2C(=O)NC(=O)[C@H]2CC1C)c1ccccc1</smiles>

Andrimid

Figure 1. Succinimides in pharmaceuticals and drugs.

Chiral succinimides are valuable synthetic intermediates ${ }^{[5]}$ and structural motifs in molecules with interesting biological activities. ${ }^{[4,6]}$ Among the different methodologies available for

Computational and NMR studies support the hydrogen-bonding activation role of the catalyst and the origin of the stereoselectivity of the process.

the synthesis of chiral $\alpha$-substituted succinimides, ${ }^{[7]}$ the asymmetric conjugate addition to maleimides ${ }^{[8]}$ has emerged as a powerful tool for the synthetic chemist, specially using chiral organocatalysts. ${ }^{[9]}$ Thus, very high enantioselectivities have been obtained in the conjugate addition of ketones, ${ }^{[10]}$ aldehydes ${ }^{[11]}$ and a wide variety of activated methylenes and methines, ${ }^{[12]}$ to $N$-substituted maleimides. Regarding activated nucleophiles, 1,3-diketones, ${ }^{[12 \mathrm{a}]}$ malonates, ${ }^{[12 \mathrm{c}]} \quad \beta$ ketoesters, ${ }^{[12 \mathrm{a}, \mathrm{c}, \mathrm{d}]} \quad$ anthrones, ${ }^{[12 \mathrm{~b}, \mathrm{~g}]} \quad$ oxindoles, ${ }^{[12 \mathrm{f}]} \quad \alpha$ cyanoacetates, ${ }^{[12 \mathrm{j}, \mathrm{k}]} \quad \alpha$-nitroacetates, ${ }^{[121]} \alpha$-isocyanoacetates, ${ }^{[12 \mathrm{~m}]}$ azlactones, ${ }^{[12 \mathrm{i}]}$ pyrazolones, ${ }^{[12 \mathrm{n}]}$ and oxazolones, ${ }^{[12 \mathrm{o}]}$ have been successfully used as Michel donors, typically employing bifunctional chiral Brønsted base/hydrogen bonding organocatalysts (Figure 2). ${ }^{[9 f]}$<smiles>C=CC1CN2CCC1(C)CN2C(O)c1ccnc2ccc(OC)cc12</smiles><smiles>CN(C(=S)Nc1ccc([N+](=O)[O-])cc1)C(c1ccccc1)c1ccccc1</smiles>

3<smiles>[R]N([R])[C@H]1CCCC[C@H]1N(C)c1nc2ccccc2n1C</smiles>

5a, $\mathrm{R}^{1}=\mathrm{R}^{2}=\mathrm{H}$

$5 \mathbf{b}, R^{1}=R^{2}=M e$

5c, $R^{1}=R^{2}=E t$

$\mathbf{5 d}, R^{1}, R^{2}=2,5$-dimethylpyrrol-1-yl

5e, $R^{1}, R^{2}=$ piperidin-1-yl

Figure 2. Chiral bifunctional Brønsted base/hydrogen bonding organocatalysts. 
Very recently, the utility of chiral 2-aminobenzimidazoles as organocatalysts for the asymmetric conjugate addition to nitroolefins has been disclosed by our group ${ }^{[13]}$ and others ${ }^{[14]}$ which benefits from 2-aminobenzimidazole's characteristic dual hydrogen-bonding catalysis. ${ }^{[15]}$ Thus, catalyst $5 \mathbf{b}$ (Figure 2 ), in which the distance between hydrogen atoms $\mathrm{H}_{\mathrm{a}}$ and $\mathrm{H}_{\mathrm{b}}$ is in between the reported distances for the highly enantioselective thiourea ${ }^{[16]}$ and squarimide-derived organocatalysts, ${ }^{[17]}$ is a very active and general catalyst for the enantioselective conjugate addition of malonates, $\beta$-ketoesters, and 1,3-diketones to a wide range of conjugated nitroalkanes in the presence of TFA as cocatalyst. ${ }^{[13]}$

Regarding the addition to maleimides, we have recently demonstrated that the recyclable chiral 2-aminobenzimidazole catalyst $\mathbf{5 f}$, efficiently catalyzes the direct conjugate addition of different 1,3-dicarbonyl compounds to maleimides to give the corresponding chiral (S)-succinimides with very high enantiocontrol. ${ }^{[18]}$ For this process, we tentatively proposed a transition state model where the benzimidazole-derived organocatalyst $\mathbf{5 f}$ carried out a bifunctional activation of the nucleophile and the electrophile. ${ }^{[18]}$

Herein, we report the full study on this reaction including detailed NMR mechanistic studies as well as DFT calculations in order to elucidate on the catalytic active species and the $\mathrm{H}$ bond network between catalyst, nucleophile and maleimide responsible for the observed reactivity and enantioselectivity.

\section{Results and Discussion}

The synthesis of catalysts 5a-e has been already described $^{[18 \mathrm{a}]}$ and involves, as a common initial step, a solventfree aromatic nucleophilic substitution of $(1 R, 2 R)-1,2-$ diaminocyclohexane to 2-chlorobenzimidazole followed by the corresponding derivatization of the primary amine. $\mathrm{C}_{2}-$ symmetric catalysts $\mathbf{5} \mathbf{f}^{[18 a]}$ and $\mathbf{5 g}$ were prepared by a twofold aromatic substitution with 2-chlorobenzimidazole and 1methyl-2-chlorobenzimidazol, respectively.

In our previous optimization study, ${ }^{[18,19]}$ we demonstrated the superiority of dimeric catalyst $5 \mathbf{f}$ over benzimidazolederived catalysts $\mathbf{5 a - e}$ in the conjugate addition of different 1,3dicarbonyl compounds to maleimides. For instance, the $5 \mathbf{f}(10$ mol-\%)-catalyzed conjugate addition of acetylacetone (0.3 $\mathrm{mmol})$ to maleimide $(0.15 \mathrm{mmol})$ in the presence of TFA (10 mol-\%) as cocatalyst and toluene as solvent, led to succinimide 6a in an excellent $94 \%$ yield and $97 \%$ ee (Figure 3). We also showed, that the use of hydrogen-bond forming solvents such as $\mathrm{H}_{2} \mathrm{O}$ or $\mathrm{MeOH}$, led to a drastic decrease in stereoselectivity. ${ }^{[18]}$ Accordingly, and in order to confirm the hydrogen bonding activation mode of catalyst $\mathbf{5} \mathbf{f}$ in this reaction, we initially studied the aptitude of catalyst $5 g$ (Figure $2, \mathrm{R}^{1}=$ $\mathrm{R}^{2}=\mathrm{Me}$ ) in the process under the previously optimized reaction conditions. As depicted in Figure 3, only an 11\% yield of succinimide $6 \mathbf{a}$ was obtained in a lower $48 \%$ ee, confirming the importance of the presence of the secondary amine for the optimal hydrogen-bonding catalyst performance.

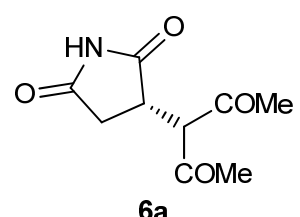

5a, $42 \%, 41 \%$ ee $\mathbf{5 e}, 89 \%, 11 \%$ ee

$\mathbf{5 b}, 99 \%, 15 \%$ ee $\mathbf{5 f}, 94 \%, 97 \%$ ee

5c, $90 \%, 13 \%$ ee $\mathbf{5 g}, 11 \%, 48 \%$ ee

5d, $<5 \%$, -
Figure 3. Conjugate addition of acetylacetone to maleimide catalyzed by $\mathbf{5 f}$ and $\mathbf{5 g}$.

Further optimization of the reaction conditions employing organocatalyst $5 f$ (Table 1) showed a slight decrease in the enantioselectivity of the process when the conjugate addition was performed at $0{ }^{\circ} \mathrm{C}$, affording 6 a in a $94 \%$ ee (entry 2). With respect to the role of the acid cocatalyst TFA in the reaction, a significant decrease in the enantioselectivity of the reaction $(51 \%$ ee) was detected in the absence of TFA (Table 1 , entry 3 ). This result clearly evidenced the higher ability of the protonated catalyst for hydrogen-bonding activation. Notably, a complete deactivation of the catalyst was observed when using a twofold excess (20 mol- $\%$ ) of cocatalyst (Table 1, entry 4). Also, dependence of the enantioselectivity of the process on catalyst loading was observed (Table 1, entries 5 and 6). Finally, further optimization of catalyst loading revealed that only 1 mol- $\%$ of 5f/TFA was able to afford a highly efficient reaction though the enantioselectivity of the process slightly decreased to $93 \%$ (Table 1 , entry 7 ).<smiles>CC(=O)CC(C)=O</smiles><smiles>CC(=O)C(C(C)=O)[C@H]1CC(=O)NC1=O</smiles>

$6 \mathbf{a}$

Table 1. Enantioselective conjugate addition of acetylacetone to maleimide catalyzed by chiral 2-aminobenzimidazole catalyst $\mathbf{5 f ^ { \text { a) } }}$

\begin{tabular}{llllll}
\hline Entry & $\begin{array}{l}\mathbf{5 f} \\
(\mathrm{mol}-\%)\end{array}$ & $\begin{array}{l}\text { TFA }(\mathrm{mol}- \\
\mathbf{\%})\end{array}$ & $\begin{array}{l}\mathrm{T} \\
\left({ }^{\circ} \mathrm{C}\right)\end{array}$ & $\begin{array}{l}\text { Yield } \\
(\%)^{\mathrm{b})}\end{array}$ & $\begin{array}{l}\text { ee } \\
\left.(\%)^{\mathrm{c}}\right)\end{array}$ \\
\hline 1 & 10 & 10 & 30 & 94 & 97 \\
2 & 10 & 10 & 0 & 95 & 94 \\
3 & 10 & - & 30 & 94 & 51 \\
4 & 10 & 20 & 30 & $<5$ & - \\
5 & 30 & 30 & 30 & 85 & 87 \\
6 & 100 & 100 & 30 & 81 & 83 \\
7 & 1 & 1 & 30 & 96 & 93 \\
\hline
\end{tabular}

a) Reaction conditions: acetylacetone $(0.3 \mathrm{mmol})$, maleimide $(0.15 \mathrm{mmol})$, 5 f (10 mol-\%, $0.015 \mathrm{mmol}, 0.05 \mathrm{M})$, TFA (10 mol-\%, $0.015 \mathrm{mmol})$, solvent $(0.3 \mathrm{~mL})$, r.t., $24 \mathrm{~h} .{ }^{\text {b) }}$ Isolated yield after flash chromatography. ${ }^{\text {c) }}$ Determined by chiral HPLC [OD-H, hexane/ $i \mathrm{PrOH}: 85 / 15,1 \mathrm{~mL} / \mathrm{min}$ ].

At high catalyst concentrations (Table 1, entries 5 and 6), product racemization due to thermodynamic control of the process was discharged, since the enantioselectivity of the reaction kept constant within the course of the experiment when a $0.1 \mathrm{M}$ catalyst concentration was used in the conjugate 
addition (Figure 4). This was also confirmed when succinimide 6a $(97 \%$ ee) was submitted to the optimal reaction conditions [5f $(10 \mathrm{~mol}-\%)$, TFA (10 mol-\%), toluene, $30{ }^{\circ} \mathrm{C}$ ] in the presence of a different nucleophile such as 3acetyldihydrofuran-2(3H)-one, being compound $\mathbf{6 a}$ only detected in the crude reaction mixture (TLC and ${ }^{1} \mathrm{HNMR}$ ) with the same optical purity (Scheme 1).

Figure 4. Ee versus time for the conjugate addition of acetylacetone to maleimide catalyzed by $5 \mathbf{f} /$ TFA.

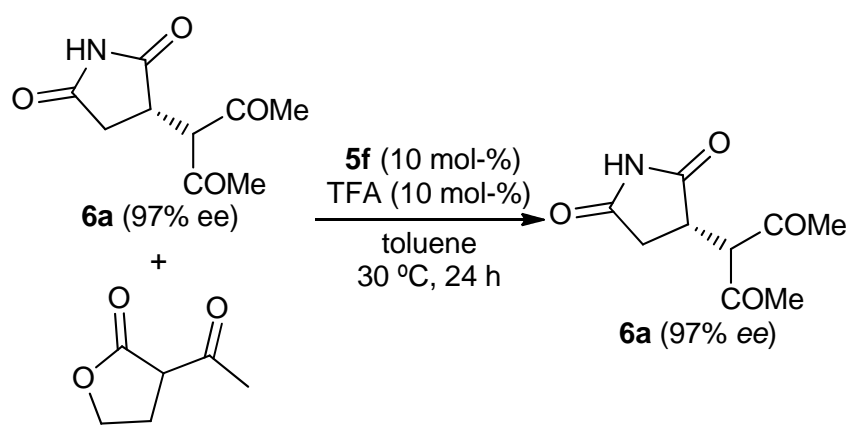

Scheme 1. Racemization study with $\mathbf{6 a}$.

Additional studies on catalyst concentration were performed on the model reaction. The ee values obtained at different catalyst concentrations (Table 2) were fairly consistent with the diffusion coefficients $(D)$ of 5f/TFA, strongly indicating that the degree of hydrogen-bonded self-association of bifunctional organocatalyst 5f/TFA in solution plays a crucial role in determining the enantioselectivity of the process. $^{[20]}$

Table 2. Diffusion coefficients of $5 \mathbf{f} /$ TFA (10 mol-\%) at different concentrations versus enantioselectivities in the asymmetric addition of acetylacetone to maleimide.

\begin{tabular}{llll}
\hline Entry & $\mathbf{5 f} /$ TFA Conc. (molar) & $D / D^{\text {Tol a) }}$ & $e e(\%)^{\text {b) }}$ \\
\hline 1 & 0.01 & 0.33 & 96 \\
2 & 0.05 & 0.31 & 97 \\
3 & 0.1 & 0.20 & 88 \\
\hline
\end{tabular}

a) Diffusion coefficients $D\left(10^{-10} \mathrm{~m}^{2} \mathrm{~s}^{-1}\right)$ at room temperature for 5f/TFA corrected with respect to the solvent (toluene- $\mathrm{d}_{8}$ ) at different molar $(\mathrm{M})$ concentrations. ${ }^{\text {b) }}$ Determined by chiral HPLC [OD-H, hexane/iPrOH: 85/15, $1 \mathrm{~mL} / \mathrm{min}$ ].

Under the optimized reaction conditions (Table 1, entry 1), the generality of the conjugate addition reaction with respect to the nucleophile and the maleimide acceptor was then investigated. As depicted in Figure 5, the conjugate addition of acetylacetone to different $\mathrm{N}$-alkyl- and $\mathrm{N}$-aryl maleimides afforded the corresponding 1,4-adducts $\mathbf{6 b - 6 g}$ in good yields and excellent enantioselectivities. All the studied substrates afforded similar levels of ee than maleimide (95-97\% ee). The 5f-catalyzed conjugate addition reaction was also applicable to $\alpha$-substituted 3-methylpentane-2,4-dione, which afforded after addition to $N$-phenylmaleimide compound $\mathbf{6 h}$ in a $50 \%$ yield and a high $91 \%$ ee. Regarding non-symmetrical $\beta$-diketones, the addition of 1-phenylbutane-1,3-dione to maleimide afforded compound $\mathbf{6 i}$ in a $97 \%$ yield as a 58/42 mixture of diastereomers, both of them obtained with excellent enantioselectivity. The addition of the cyclic 2acetylcyclopentanone to $N$-phenylmaleimide afforded compound $\mathbf{6 j}$ in a $93 \%$ yield as a $93 / 7$ mixture of diastereomers, both of them obtained with very high enantioselectivity (Figure $5)$. 6a, 94\%, 97\% ee<smiles>CC(=O)C(C)(C)C1CC(=O)NC1=O</smiles>

$6 h, 50 \%, 91 \%$ ee<smiles>CC(=O)C(C(C)=O)[C@H]1CC(=O)NC1=O</smiles>

6i, $97 \%$, dr: 58/42 $97 / 94 \%$ ee<smiles>CC(=O)C(C(C)=O)[C@H]1CC(=O)NC1=O</smiles><smiles>CC(=O)C(C(C)=O)[C@H]1CC(=O)NC1=O</smiles>
6c, $\mathrm{R}=\mathrm{Et}, 69 \%, 97 \%$ ee 6d, $\mathrm{R}=\mathrm{Bn}, 65 \%, 95 \%$ ee<smiles>CC(=O)C(C(C)=O)[C@H]1CC(=O)NC1=O</smiles>

6e, $\mathrm{Ar}=\mathrm{Ph}, 100 \%, 97 \%$ ee 6f, $\mathrm{Ar}=4-\mathrm{BrC}_{6} \mathrm{H}_{4}, 98 \%, 96 \%$ ee 6g, $\mathrm{Ar}=4-\mathrm{AcC}_{6} \mathrm{H}_{4}, 92 \%, 95 \%$ ee<smiles>CC(=O)[C@]1(C2CC(=O)[NH+](c3ccccc3)C2=O)CCCC1=O</smiles>

6j, 93\%, dr: 97/3 $95 / 98 \%$ ee 6b, $R=M e, 69 \%, 97 \%$ ee

Figure 5. Conjugate addition of 1,3-diketones to maleimides catalyzed by $\mathbf{5 f}$.

The optimized catalytic system proved to be effective for $\beta$-ketoesters as well, being the expected products formed in high yields, moderate to good diastereoselectivity, and very high levels of enantioselectivity (Figure 6). The synthesis of compounds 6j-6n resulted especially interesting, since evidenced the ability of the catalytic system to synthesize adjacent quaternary/tertiary stereogenic centres with excellent enantioselectivities.

We finished the nucleophile scope with malonates. Interestingly, catalyst $\mathbf{5 f}$ performed better in the absence of TFA for these nucleophiles. Then, when dimethyl malonate reacted, under the optimized reaction condition with maleimide, compound 60 was obtained in an $81 \%$ ee and a very low $23 \%$ isolated yield (Figure 6). This was probably due to the lower acidity of the nucleophile compared to 1,3-diketones and $\beta$ ketoesters, thus requiring a catalyst with an stronger basic character. This was confirmed by performing the reaction in the absence of TFA, which afforded compound 60 in a $78 \%$ ee and a higher $74 \%$ isolated yield. With respect to yield, a similar tendency was observed in the reaction with $\mathrm{N}$-methyl and $\mathrm{N}$ phenyl maleimides which afforded compounds $\mathbf{6 p}$ and $\mathbf{6 q}$, in 99\% ee and high yields in the absence of TFA (Figure 6). 
<smiles>CC(=O)[C@]1(C2CC(=O)[NH+](c3ccccc3)C2=O)CCOC1=O</smiles>

6k, $96 \%, d r: 73 / 27$ $97 / 86 \%$ ee<smiles>CC(=O)C1(C(C)=O)CCc2ccccc2C1=O</smiles>

$6 \mathrm{~m}, 98 \%, d r: 99 / 99$ $76 / 24 \%$ ee<smiles>COC(=O)C(C(C)=O)[C@H]1CC(=O)NC1=O</smiles>

6o, $\mathrm{R}=\mathrm{H}, 23 \%, 74 \%$ ee $(10 \%$ TFA)

6o, $\mathrm{R}=\mathrm{H}, 81 \%, 78 \%$ ee (0\% TFA)

$6 p, R=M e, 7 \%, 90 \%$ ee (10\% TFA)

6p, $\mathrm{R}=\mathrm{Me}, 99 \%, 99 \%$ ee $(0 \%$ TFA)

6q, $\mathrm{R}=\mathrm{Ph}, 40 \%, 83 \%$ ee $(10 \%$ TFA $)$

$6 q, R=M e, 83 \%, 99 \%$ ee ( $0 \%$ TFA)

Figure 6. Conjugate addition of $\beta$-ketoesters and dimethyl malonate to maleimides catalyzed by $5 \mathbf{f}$.

The synthetic utility of the catalytic methodology was confirmed by gram-scale experiments $(5-20 \mathrm{mmol}$ of Michael acceptor) for the synthesis of succinimides $6 \mathbf{a}, \mathbf{6 d}, \mathbf{6 g}$, and $\mathbf{6 k}$ which were obtained as optically pure compounds $(>99 \% e e)$ in high yields after filtration from the crude reaction mixture (Figure 7). ${ }^{[21]}$
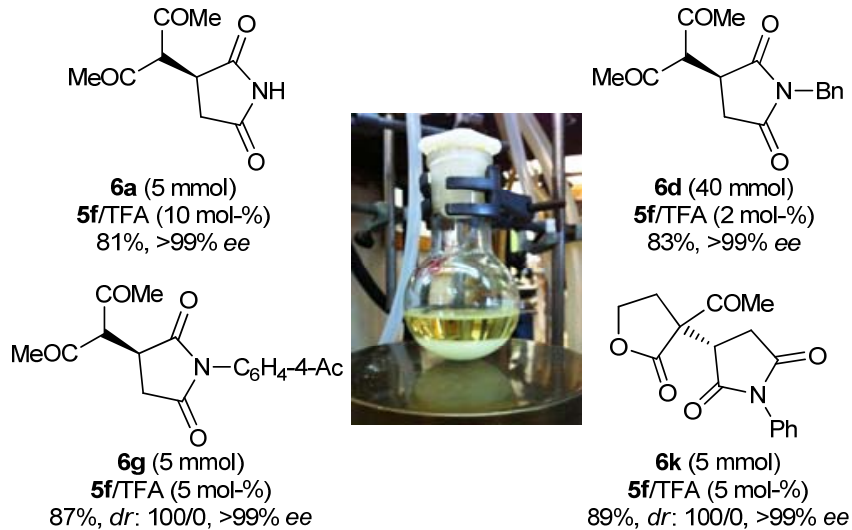

6k $(5 \mathrm{mmol})$ 5f/TFA (5 mol-\%) $89 \%, d r: 100 / 0,>99 \%$ ee

Figure 7. Gram-scale synthesis of chiral succinimides 6.
The functional characteristics of the synthesized chiral 1,3-dicarbonyl compounds 6 was used for the synthesis of optically active pyrazol-derived succinimides. ${ }^{[22]}$ Thus, compounds 6a $(97 \%$ ee) and $\mathbf{6 e}(97 \% e e)$ were transformed in succinimides $7 \mathbf{a}(99 \% e e)$ and $7 \mathbf{e}(99 \% e e)$ by treatment with $\mathrm{N}$-phenylhidrazine in the presence of phosphotungstic acid as catalyst ( 1 mol- $\%)$ in water at r.t. (Scheme 2$)$.<smiles>[R]N1C(=O)C[C@H](C(C(C)=O)C(C)=O)C1=O</smiles>

6a, $\mathrm{R}=\mathrm{H}, 97 \%$ ee 6e, $\mathrm{R}=\mathrm{Ph}, 97 \%$ ee<smiles>[R]N1C(=O)C[C@H](c2c(C)nn(-c3ccccc3)c2C)C1=O</smiles>

7a, $\mathrm{R}=\mathrm{H}, 64 \%, 99 \%$ ee $7 e, \mathrm{R}=\mathrm{Ph}, 44 \%, 99 \%$ ee
Scheme 2. Synthesis of chiral pyrazol-derived succinimides 7.

DFT computational studies ${ }^{[23]}$ were conducted aimed at detailing the H-bond network between catalyst, nucleophile and maleimide responsible for the observed reactivity/enantioselectivity. It was assumed that the reaction is initiated with the deprotonation of the pronuclephile $(2,5-$ pentadione) by the aminobenzimidazole catalyst to form an enolate/protonated catalyst binary complex (Figure 8). Further hydrogen bonding with the maleimide renders a ternary complex that evolves to the final products through the corresponding transition state. We found that the minimum Gibbs Free energy along the reaction coordinate always corresponded to the sum of the energies of the free maleimide and the binary complex, which was thus taken as the ground $\mathrm{G}$ $=0$ energy level.
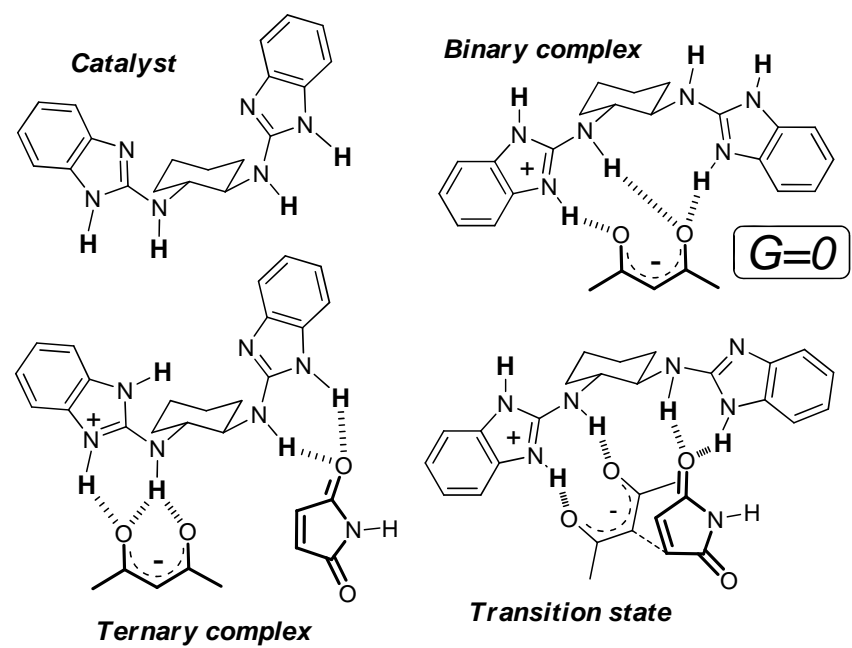

Figure 8. Main structures proposed along the reaction coordinate.

Three possible mechanistic scenarios were considered: a) in the absence of acid, the basic catalyst deprotonates and binds the nucleophile (A, Figure 9). Four NH groups are available for $\mathrm{Nu} /$ maleimide activation, arranged in a flexible and open reactive site; $b$ ) if partial protonation (1 equiv of acid) of the catalyst is considered, the neutral portion of the catalyst deprotonates the nucleophile leading to structure $\mathbf{B}$, which 
possesses a tighter reactive space decorated with 3 or $4 \mathrm{NH}$ groups for reagent activation; c) further protonation of the catalyst with a second molecule of acid would cancel the basicity of the catalyst, and only the enol form of the nucleophile could act as a nucleophile, like in structure $\mathbf{C}$, lowering its reactivity.
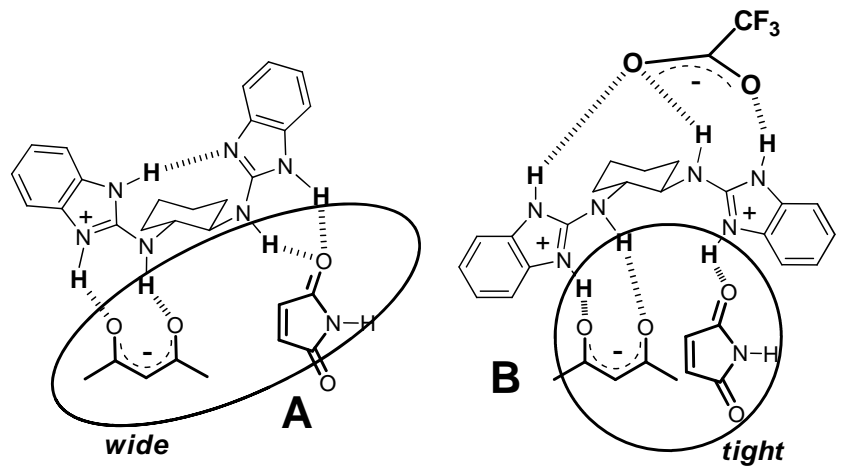

reactive space

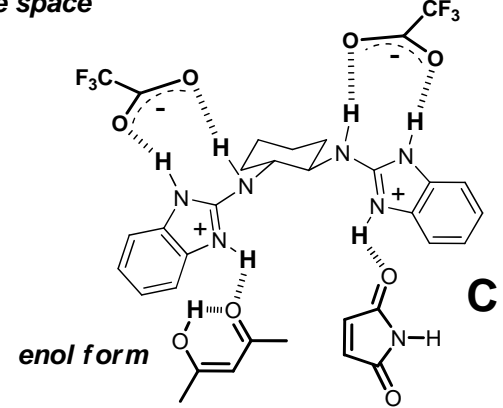

Figure 9. Computed mechanistic alternatives A, B, and C.

After an extensive conformational search, the calculated energies for the optimal transition states in model $\mathbf{A}$ predict a high reactivity and a moderate selectivity $(1.7 \mathrm{kcal} / \mathrm{mol}$ energy difference between $\mathbf{T S}_{\mathrm{A} 2}(S)$ and $\mathbf{T S}_{\mathrm{A} 2}(R)$, Figure 10), which is in fair agreement with the experimental results in the absence of acid (94\% yield, 51\% ee, Table 1, entry 4). The privileged transition structures for each enantiomer $\left(\mathbf{T S}_{\mathrm{A} 2}(S)\right.$ and $\left.\mathbf{T S}_{\mathrm{A} 2}(R)\right)$ bear an intramolecular $\mathrm{H}$ bond between the protonated and the neutral benzimidazole portions of the catalyst. As a consequence, a quite open reaction space is formed, in which the remaining four $\mathrm{NH}$ bonds are involved in a low-selective binding of the nucleophile and electrophile (see 3D picture for $\mathbf{T S}_{\mathrm{A} 2}(S)$ in Figure 10).

In contrast, the inclusion of one molecule of trifluoroacetic acid might produce a fast protonation of the catalyst (model $\mathbf{B}$ ). The $\mathrm{CF}_{3} \mathrm{COO}^{-}$anion is able to bind the two imidazole units, eliminating the possibility of an intramolecular H-bonding between them. The optimal transition structures were found, in which three of the NH groups are exposed to the trifluoroacetate anion and solvent. In this structure, the activation of the maleimide is achieved by a single $\mathrm{NH}$ bond, and two other $\mathrm{NH}$ groups bind the nucleophile, ${ }^{[24]}$ in a tight, concave reaction site. This effect increases the energy difference between the diastereomeric forms $\mathrm{TS}_{\mathbf{B}(S)}$ and $\mathrm{TS}_{\mathbf{B}(R)}$ (24.7 and $29.3 \mathrm{kcal} / \mathrm{mol}$ respectively), predicting a high reactivity and very good enantioselectivity, as experimentally found (94\% yield, $97 \%$ ee, Table 1, entry 1).
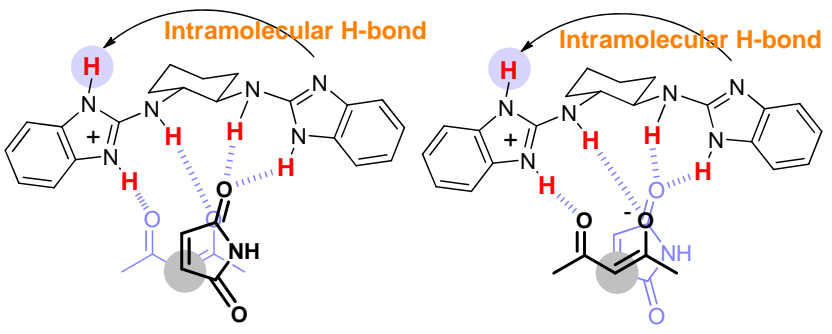

$\mathrm{TS}_{\mathrm{A} 2}(\mathrm{~S}), \Delta \mathrm{G}_{\text {toluene }}^{\ddagger}=23.6 \mathrm{kcal} / \mathrm{mol}$

$\mathrm{TS}_{\mathrm{A} 2}(\mathrm{R}), \Delta \mathrm{G}_{\text {toluene }}^{\ddagger}=25.3 \mathrm{kcal} / \mathrm{mol}$
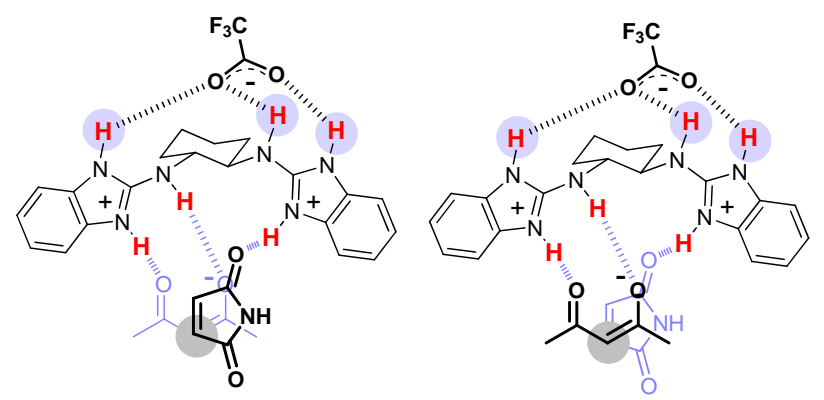

$\mathrm{TS}_{\mathrm{B} 2}(\mathrm{~S}), \Delta \mathrm{G}_{\text {toluene }}^{\ddagger}=\mathbf{2 4 . 7} \mathrm{kcal} / \mathrm{mol} \quad \mathrm{TS}_{\mathrm{B} 2}(\mathrm{R}), \Delta \mathrm{G}_{\text {toluene }}^{\ddagger}=29.3 \mathrm{kcal} / \mathrm{mol}$

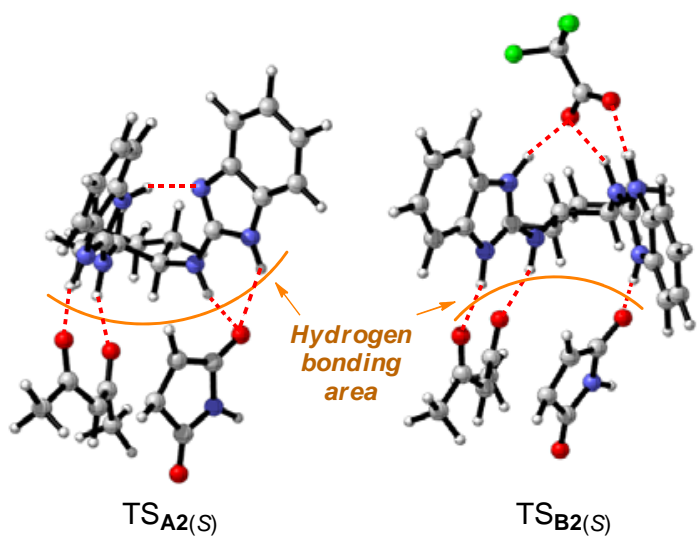

Figure 10. Main transition structures computed in models $\mathbf{A}$ and $\mathbf{B}$

As mentioned previously, the inclusion of a second molecule of TFA acid in the calculation has a deleterious effect on the reactivity of the catalyst $(<5 \%$ conversion, Table 1 , entry 4). We also offer an explanation for this effect: The double protonation of the catalyst cancels its basic character and prevents the deprotonation of the nucleophile. Only the enol form of the nucleophile is available for the attack to the maleimide, and both enol and maleimide appear single bonded to the catalyst, as in model C. In this unfavourable scenario it is not surprising to find a high computed activation energy (46.3 $\mathrm{kcal} / \mathrm{mol}$ ).

Finally, the distinct outcome shown by the malonates as nucleophiles might be related to the lower basicity of dimethyl malonate vs acetylacetone (pKa's in DMSO are 15.7 and 13.3 respectively). In fact, the deprotonation of dimethyl malonate by the TFA-protonated catalyst (mechanism B) is computed to be a disfavoured process (Figure 11). Thus, both reactions of malonate in the presence or absence of TFA proceed through mechanism A, with a computed $86 \%$ ee, in fair agreement with the experimental $74-78 \%$ ee (Figue 6), and at different rates, since the acid exerts the negative effect of lowering the available amount of the necessary free imidazole. 


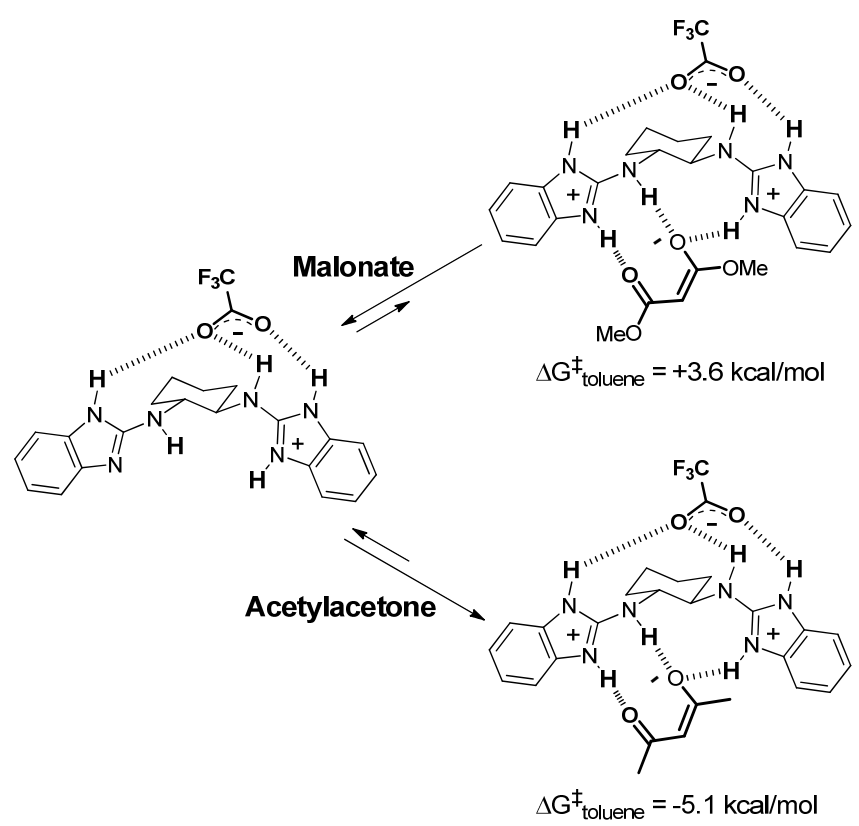

Figure 11. Different binding properties of the computed nucleophiles.

In summary, we have designed a chiral 2aminobenzimidazole catalyst $\mathbf{5 f}$, which catalyzes the direct conjugate addition of different 1,3-dicarbonyl compounds to maleimide and $N$-substituted maleimides to give the corresponding Michael adducts in very high enantiocontrol. The proposed hydrogen-bonding activation role of the catalyst and the origin of the stereoselectivity of the process have been confirmed by DFT calculations. Further studies are in progress to explore the scope of organocatalyst $\mathbf{5 f}$ in other catalytic asymmetric reactions.

\section{Experimental Section}

To a stirred solution of catalyst $\mathbf{5 f}(5.2 \mathrm{mg}, 0.015 \mathrm{mmol}, 10$ mol-\%) and maleimide $(14.6 \mathrm{mg}, 0.15 \mathrm{mmol})$ in toluene $(185 \mu \mathrm{L})$, a $1 \%(\mathrm{v} / \mathrm{v})$ TFA solution in toluene $(115 \mu \mathrm{L}, 0.015 \mathrm{mmol})$ and acetylacetone $(30.8 \mu \mathrm{L}, 0.3 \mathrm{mmol})$ were added. The reaction mixture was stirred at $30{ }^{\circ} \mathrm{C}$ for $24 \mathrm{~h}$. Then, the solvent was evaporated under reduced pressure to give the crude product which was purified by flash chromatography (EtOAc/hexane) to afford $27.8 \mathrm{mg}$ of pure $\mathbf{6 a}$ ( $94 \%$ yield). The selectivity of the reaction was determined by chiral HPLC before purification to be $97 \%$ ee (Chiralcel OD-H, $1 \mathrm{~mL} / \mathrm{min}$, Hexane/iPrOH: 85/15, $\lambda 210 \mathrm{~nm}$ ), $\mathrm{t}_{\mathrm{Rmay}}=28.5 \mathrm{~min}, \mathrm{t}_{\mathrm{Rmin}}=33.4 \mathrm{~min}$.

\section{Acknowledgments}

Financial support from the MEC (Projects CTQ200762771/BQU, CTQ2010-20387, and Consolider INGENIO 2010 CSD2007-00006), from the Generalitat Valenciana (PROMETEO/2009/038), FEDER, the University of Alicante, and EU (ORCA Action CM0905) is acknowledged. We also thank SGI/IZO-SGIker UPV/EHU for allocation of computational resources and Dr. Emilio Lorenzo for the DOSY NMR experiments.
[[1] a) M. K. Hargreaves, J. G. Pritchard, H. R. Dave, Chem. Rev. 1970, 70, 439-469; b) S. Muthaiah, S. H. Hong, Synthesis 2011, 1481-1485; c) J. Sperry, Synthesis 2011, 3569-3580.

[2] A. M. Crider, T. M. Kolczynski, K. M. Yates, J. Med. Chem. 1980 $23,324-326$.

[3] a) T. A. Glauser, E. Perucca, in Treatment of Epilepsy, 3rd. Ed., (Eds.: S. Shorvon, E. Perucca, J. Engel Jr.), Wiley-Blackwell, Oxford, 2009, pp. 499-509; b) P. Striano, C. Minetti, Nat. Rev. Neurol. 2010, 6, 420-421.

[4] a) A. Fredenhagen, S. Y. Tamura, P. T. M. Kenny, H. Komura, Y. Naya, K. Nakanishi, J. Am. Chem. 1987, 109, 4409-4411; b) J. Needham, M. T. Kelly, M. Ishige, R. J. Andersen, J. Org. Chem. 1994, 59, 2058-2063.

[5] For selected examples, see: a) E. J. Yoo, M. Wasa, J.-Q. Yu, J. Am. Chem. Soc. 2010, 132, 17378-17380; b) S. Das, D. Addis, L. R. Knöpke, U. Bentrup, K. Junge, A. Brückner, M. Beller, Angew. Chem. Int. Ed. 2011, 50, 9180-9184.

[6] S. Ahmed, Drug Des. Discovery, 1996, 14, 77-89; b) M. L. Curtin, R. B. Garland, H. R. Heyman, R. R. Frey, M. R. Michaelides, J. Li, L. J. Pease, K. B. Glaser, P. A. Marcotte, S. K. Davidsen, Bioorg. Med. Chem. Lett. 2002, 12, 2919-2923; c) J. Pohlmann, T. Lampe, M. Shimada, P. G. Nell, J. Pernerstorfer, N. Svenstrup, N. A. Brunner, G. Schiffer, C. Freiberg, Bioorg. Med. Chem. Lett. 2005, 15, 1189-1192.

[7] For selected examples, see: a) B. Alcaide, P. Almendros, G. Cabrero, P. Ruiz, Org. Lett. 2004, 7, 3981-3984. b) T. Mashiko, N. Kumagai, M. Shibasaki, Org. Lett. 2008, 10, 2725-2728. c) A. Wilsily, E. Fillion, Org. Lett. 2008, 10, 2801-2804.

[8] For recent examples about the asymmetric rhodium-catalyzed asymmetric 1,4-addition of arylboronic acids to maleimides, see: R Shintani, K. Ueyama, I. Yamada, T. Hayashi, Org. Lett. 2004, 6, 3425-3427; b) R. Shintani, W.-L. Duan, T. Nagano, A. Okada, T. Hayashi, Angew. Chem. Int. Ed. 2005, 44, 4611-4614; c) R. Shintani, W.-L. Duan, T. Hayashi, J. Am. Chem. Soc. 2006, 128, 5628-5629.

[9] D. Almaşi, D. A. Alonso, C. Nájera, Tetrahedron: Asymmetry 2007 18, 299-365; b) S. B. Tsogoeva, Eur. J. Org. Chem. 2007, 1701-1716; c) J. L. Vicario, D. Badía, L. Carrillo, Synthesis 2007 2065-2092; d) S. Sulzer-Mossé, A. Alexakis, Chem. Commun. 2007, 3123-3135; e) Organocatalytic Enantioselective Conjugate Addition Reactions. A Powerful Tool for the Stereocontrolled Synthesis of Complex Molecules, (Eds. J. L. Vicario, D. Badia, L. Carrillo, E. Reyes), RSC, Cambridge, 2010; f) D. A. Alonso, in Enantioselective Organocatalyzed Reactions II. Asymmetric C-C Bond Formation Processes, (Ed.: R. Mahrwald), Springer, Heidelberg, 2011, pp. 41-185.

[10] a) F. Yu, X. Sun, Z. Jin, S. Wen, X. Liang, J. Ye, Chem. Commun 2010, 4589-4591; b) J. Wang, M.-M. Zhang, S. Zhang, Z.-A. Xu, H. Li, X.-H. Yu, W. Wang, Synlett 2011, 463-476.

[11] a) G.-L. Zhao, Y. Xu, H. Sundén, L. Eriksson, M. Sayah, A. Córdova, Chem. Commun. 2007, 734-735; b) F. Xue, L. Liu, S. Zhannng, W. Duan, W. Wang, Chem. Eur. J. 2010, 16, 7979-7982; c) F. Yu, Z. Jin, H. Huang, T. Ye, X. Liang, J. Ye, Org. Biomol. Chem. 2010, 8 , 4767-4774; d) T. Miura, S. Nishida, A. Masuda, N. Tada, A. Itoh, Tetrahedron Lett. 2011, 52, 4158-4160; e) T. Miura, A. Masuda, M. Ina, K. Nakashima, S. Nishida, N. Tada, Tetrahedron: Asymmetry 2011, 22, 1605-1609; f) Z.-W. Ma, Y.-X. Liu, P.-L. Li, H. Ren, Y. Zhu, J.-C. Tao, Tetrahedron: Asymmetry 2011, 22, 1740-1748.

[12] a) G. Bartoli, M. Bosco, A. Carlone, A. Cavalli, M. Locatelli, A Mazzanti, P. Ricci, L. Sambri, P. Melchiorre, Angew. Chem. Int. Ed. 2006, 45, 4966-4870; b) J. Shen, T. T. Nguyen, Y.-P. Goh, W. Ye, X. Fu, J. Xu, C.-H. Tan, J. Am. Chem. Soc. 2006, 128, 13692-13693; c) W. Ye, Z. Jiang, Y. Zhao, S. L. M. Goh, D. Leow, Y.-T. Soh, C.H. Tan, Adv. Synth. Catal. 2007, 349, 2454-2458; d) Z. Jiang, Y. Pan, Y. Zhao, T. Ma, R. Lee, Y. Yang, K.-W. Huang, M. W. Wong, C.-H. Tan, Angew. Chem. Int. Ed. 2009, 48, 3627-3631; e) C. S. Cucinotta, M. Kosa, P. Melchiorre, A. Cavalli, F. L. Gervasio, Chem Eur. J. 2009, 15, 7913-7921; f) Y.-H. Liao, X.-L. Liu, Z.-J. Wu, L.F. Cun, X.-M. Zhang, W.-C. Yuan, Org. Lett. 2010, 12, 2896-2899; g) A. Zea, G. Valero, A.-N. R. Alba, A. Moyano, R. Rios, Adv. Synth Catal. 2010, 352, 1102-1106; h) X. Li, S. Hu, Z. Xi, L. Zhang, S. Luo, J.-P. Cheng, J. Org. Chem. 2010, 75, 8697-8700; i) A.-N. R. Alba, G. Valero, T. Calbet, M. Font-Bardía, A. Moyano, R. Rios, Chem. Eur. J. 2010, 16, 9884-9889; j) J.-J. Wang, X.-J. Dong, W.-T. 
Wei, M. Yan, Tetrahedron: Asymmetry 2011, 22, 690-696; k) Y.-H. Liao, X.-L. Liu, Z.-J. Wu, X.-L. Du, X.-M. Zhang, W.-C. Yuan, Adv. Synth. Catal. 2011, 353, 1720-1728; 1) S. Shirakawa, S. J. Terao, R. He, K. Maruoka, Chem. Commun. 2011, 47, 10557-10559; m) J.-F. Bai, L.-L. Wang, L. Peng, Y.-L. Guo, L.-N. Jia, F. Tian, G.-Y. He, X.-Y. Xu, L.-X. Wang, J. Org. Chem. 2012, 77, 2947-2953; n) A. Mazzanti, T. Calbet, M. Font-Bardía, A. Moyano, R. Rios, Org. Biomol. Chem. 2012, 10, 1645-1652; o) A.-N. R. Alba, G. Valero, T. Calbet, M. Font-Bardía, A. Moyano, R. Rios, N. J. Chem. 2012, 36, 613-618.

[13] D. Almaşi, D. A. Alonso, E. Gómez-Bengoa, C. Nájera, J. Org. Chem. 2009, 74, 6163-6168.

[14] a) L. Zhang, M.-M. Lee, S.-M. Lee, J. Lee, M. Cheng, B.-S. Jeong, H.-g. Park, S.-S. Jew, Adv. Synth. Catal. 2009, 351, 3063-3066; b) J. Lin, H. Tian, Y.-J. Jiang, W.-B. Huang, L.-Y. Zheng, S.-Q. Zhang, Tetrahedron: Asymmetry 2011, 22, 1434-1440; c) M. Lee, L. Zhang, Y. Park, H.-G. Park, Tetrahedron 2012, 68, 1452-1459.

[15] a) A. G. Doyle, E. N. Jacobsen, Chem. Rev. 2007, 107, 5713-5743; b) X. Yu, W. Wang, Chem. Asian J. 2008, 3, 516-532; c) Y. Sohtome, K. Nagasawa, Synlett 2010, 1-22; d) Hydrogen Bonding in Organic Synthesis, (Eds. M. Petri, M. Pihko), WILEY-VCH, Weinheim, 2009.

[16] a) H. Miyabe, Y. Takemoto, Bull. Chem. Soc. Jpn. 2008, 81, 785-795. b) S. Connon, Synlett 2009, 354-376.

[17] J. P. Malerich, K. Hagihara, V. H. Rawal, J. Am. Chem. Soc. 2008, 130, 14416-14417.
[18] a) E. Gómez-Torres, D. A. Alonso, E. Gómez-Bengoa, C. Nájera, Org. Lett. 2011, 13, 6106-6109; b) E. Gómez-Torres, D. A. Alonso, E. Gómez-Bengoa, C. Nájera, Synfacts 2012, 8, 0100.

[19] For the full study, see the Supporting Information.

[20] For a self-association-free dimeric cinchona alkaloid organocatalyst, see: J. W. Lee, T. H. Ryu, J. S. Oh, H. Y. Bae, H. B. Jang, C. E. Song, Chem. Commun. 2009, 7224-7226.

[21] The enantioselectivity of succinimides 6 was determined to be $>99 \%$ ee on the crude reaction mixture, before filtration.

[22] For the synthesis of other chiral 3-substituted heterocyclic succinimides by asymmetric organocatalyzed conjugate addition to maleimides, see references $12 \mathrm{f}, 12 \mathrm{~h}, 12 \mathrm{i}, 12 \mathrm{n}$ and $12 \mathrm{o}$.

[23] Calculations carried out in a solvent model (IEFPCM, toluene) at B3LYP/6-311++G** level. The values used in the discussion correspond to Free Gibbs energies (G). For further details, see SI.

[24] Tighter H-bonding to the nucleophile than to the electrophile during transition state have also been observed in related addition reactions, see: a) A. Hamza, G. Schubert, T. Soós, I. Papai, J. Am. Chem. Soc. 2006, 128, 13151-13160. b) E. Gómez-Bengoa, A. Linden, R. López, I. Múgica-Mendiola, M. Oiarbide, C. Palomo, J. Am. Chem. Soc. 2008, 130, 7955-7966.

Received: ((will be filled in by the editorial staff)) Published online: ((will be filled in by the editorial staff)) 
The chiral 2-aminobenzimidazolederived catalyst $\mathbf{5 f}$ serves as very efficient and selective bifunctional organocatalyst in the asymmetric conjugate addition of 1,3-dicarbonyl compounds to maleimide and $N$ substituted maleimides. Computational and NMR studies support the hydrogenbonding activation role of the catalyst and the origin of the stereoselectivity of the process.

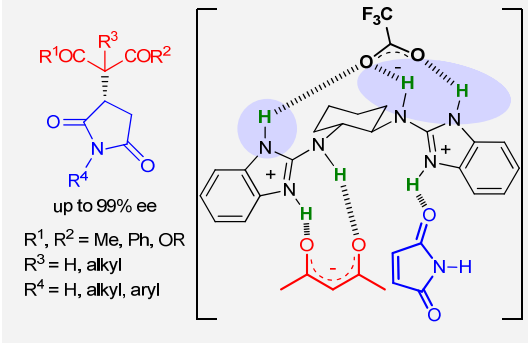

Eduardo Gómez-Torres, Diego A. Alonso,* Enrique Gómez-Bengoa, and Carmen Nájera* Page No. - Page No.

Enantioselective Synthesis of Succinimides by Michael Addition of 1,3-Dicarbonyl Compounds to Maleimides Catalyzed by a Chiral Bis(2-aminobenzimidazole) Organocatalyst

Keywords: Asymmetric catalysis / Hydrogen bonding / Michael addition / Organocatalysis / Benzimidazole 